\title{
IMPACTOS DA CUSTOMIZAÇÃO MACIÇA - ESTUDO DE CASO EM UMA INDÚSTRIA MOVELEIRA
}

\author{
Clara Yoshiko Hori Takigawa
}

Engenharia de Produção - FEPP - UNOESTE. E-mail: clarahori@unoeste.br.

\section{RESUMO}

A customização maciça é um modelo de negócio que vem agregando diferencial nas empresas que buscam consolidar-se no mercado competitivo. No entanto, a implantação desse sistema de produção gera inúmeros impactos nos diversos setores da empresa. O presente trabalho tem como objetivo abordar a customização dos produtos, focando os impactos nas principais áreas de uma empresa através do estudo de caso em uma indústria moveleira na região de Maringá. Constataram-se vários tipos de impactos nos diferentes setores da empresa e foram levantadas as causas desses impactos de modo que fosse possível sugerir melhorias para minimizá-los para torna a empresa ainda mais competitiva.

Palavras-chave: Customização. Personalização. Competitividade. Indústria moveleira. Impactos.

\section{INTRODUÇÃO}

As empresas na disputa da preferência dos clientes e com o intuito de pertencer ou aumentar a sua participação no mercado cada vez mais globalizado e competitivo, buscam estratégias empresariais que as tornam diferenciadas de seus concorrentes em produto, custo, qualidade, rapidez de entrega, flexibilidade, entre outros.

Atualmente, a competitividade é fortemente relacionada ao desenvolvimento de produtos, embora não determinada exclusivamente por esse processo, a capacidade de a organização responder satisfatoriamente às exigências que lhe são imposta pelo mercado competitivo é direta e fortemente influenciada pelos produtos que ela oferece.

Os produtos cada vez mais estão incorporando fundamentos da diferenciação maciça, as quais criam e utilizam-se tecnologias flexíveis e métodos de gerenciamento para desenvolver e produzir novos produtos e serviços, que mais adequadamente atendam aos gostos individuais dos potenciais consumidores.

Para Poter (1989), o sucesso da empresa está intimamente ligado à satisfação do cliente, ou seja, o produto que ela oferece deve saciar as necessidades implícitas e explícita de quem as consome. Para isso a empresa deverá focar-se na personalização, especialização, sofisticação e tecnologia.

Conhecida no jargão das empresas como customização, a personalização maciça, é um modelo de negócios que vem agregando diferencial nas empresas que buscam consolidar-se no 
mercado competitivo. No entanto, as empresas que adotam essa técnica devem estar dispostas a terem uma linha de produção flexível e a trabalharem com os diversos impactos que ela ocasiona.

O presente trabalho tem como objetivo abordar a customização dos produtos, focando os impactos nas principais áreas de uma empresa. Será apresentado o estudo de caso em uma indústria moveleira situada no noroeste do Paraná a qual possui a política da customização.

\section{METODOLOGIA}

Com o conhecimento das vantagens competitivas da produção customizada, buscou-se verificar neste estudo de caso quais os reais impactos dessa modalidade dentro de uma empresa.

No primeiro momento realizou-se a descrição, o acompanhamento e a análise das adaptações que cada etapa do processo do produto sofre para atender os produtos customizados, começando pela venda do produto até a sua expedição.

Fez-se um diagnóstico de falhas e impactos dos setores com a produção customizada e propôs-se uma maneira de minimizar esse impacto, de forma a tornar a empresa mais competitiva no mercado através da otimização do processo, redução de custo e melhoria da qualidade.

\subsection{A empresa}

Este trabalho foi realizado em uma indústria moveleira situada no noroeste do Paraná, região de Maringá. A empresa atua no ramo de móveis de estofados em tecido luxuosos desde a sua fundação no segundo semestre de 1998.

Reconhecida nacionalmente e internacionalmente nesse ramo, a empresa fornece produtos a consumidores de classe social A e AA, em todo território brasileiro e em alguns países como Canadá, Chile, Estados Unidos, Nigéria, Porto Rico, Uruguai. Para atender esse público, a empresa conta com aproximadamente 180 funcionários que colaboram para uma média de produção de 3.000 peças por mês.

Uma característica importante da empresa é a flexibilidade existente na capacidade de modificação de algumas características do produto, ou seja, a customização do produto. Tal fator proporciona diferenciação no atendimento de seus clientes tornando a empresa mais competitiva nesse mercado, pois a classe social do consumidor desse produto possui um perfil que busca um produto de altíssima qualidade, diferenciado e que possua suas características pessoais. Essa peculiaridade da empresa representa atualmente $45 \%$ da produção mensal de todos os produtos. 
A empresa trabalha com a fabricação e comercialização de sofás e poltronas estofadas em tecido, possuindo em média 160 tipos de modelos diferenciados, entre os quais o cliente ainda poderá variar entre um, dois, três e quatro lugares, poltrona, chaise e puff.

Esses produtos podem ser customizados de acordo com a vontade e/ou necessidade de cada cliente através da alteração de tamanhos (comprimento e altura) e nos acessórios (pés, bases, articulações, composições de tecidos, vivos, franja, entre outros).

\section{RESULTADOS}

Através do acompanhamento e das observações feitas diretamente no processo de produção do produto customizado, levantou-se as seguintes falhas geradas pelo impacto da customização nas etapas do processo do produto.

O aumento do tempo do processo é algo verificado em todas as etapas do produto que são causados pelos mais diversos motivos (Quadro 1). Em algumas fases essa variação é mínima e em outras é consideravelmente grande, o que se torna significativo para a empresa em relação ao custo de mão-de-obra do operador de cada etapa (Quadro 2). A porcentagem do aumento do tempo foi feito baseado no tempo médio de execução de produtos padrões.

Quadro 1. Variação média do tempo do processo de cada etapa do produto customizado

\begin{tabular}{|c|c|c|l|}
\hline Etapa & Descrição & $\begin{array}{c}\text { Aumento } \\
\text { do } \\
\text { tempo } \\
\text { (\%) }\end{array}$ & \multicolumn{1}{|c|}{ (Fator relevante para esse percentual) } \\
\hline 1 & Venda do produto & 27 & $\begin{array}{l}\text { Observac̃ões } \\
\text { - Esclarecimento das formas de customização; }\end{array}$ \\
\hline 2 & $\begin{array}{c}\text { Digitação do } \\
\text { pedido }\end{array}$ & 54 & $\begin{array}{l}\text { - Digitação da especificação da customização feita } \\
\text { pelo cliente na observação externa do pedido; }\end{array}$ \\
\hline 3 & $\begin{array}{c}\text { Conferencia do } \\
\text { pedido }\end{array}$ & 62 & $\begin{array}{l}\text { - Checagem dos dados que foram alterados com a } \\
\text { customização; }\end{array}$ \\
\hline 4 & $\begin{array}{c}\text { Suprimentos de } \\
\text { materiais }\end{array}$ & 78 & $\begin{array}{l}\text { - Planejamento especifico da aquisição do material, } \\
\text { quanto a forma de customização da matéria-prima; }\end{array}$ \\
\hline 5 & $\begin{array}{c}\text { Compra de } \\
\text { materiais }\end{array}$ & 15 & $\begin{array}{l}\text { - Verifica-se o prazo de entrega e o novo custo no } \\
\text { material; }\end{array}$ \\
\hline 7 & Ordem de & 0 & $\begin{array}{l}\text { - Não há aumento de tempo pois não é feito lote } \\
\text { especial para produtos customizados; }\end{array}$ \\
\hline 8 & Encaixe do CAD & 100 & $\begin{array}{l}\text { - É feito um novo mapa e um novo encaixe das } \\
\text { peças do produto customizado; }\end{array}$ \\
\hline 9 & Almoxarifado & 35 & $\begin{array}{l}\text { - Separação dos tecidos para os produtos } \\
\text { composês; }\end{array}$ \\
\hline
\end{tabular}




\begin{tabular}{|c|c|c|c|}
\hline 9 & Corte de espuma & 70 & - Cálculo da nova metragem; \\
\hline 9 & Corte de tecido & 100 & $\begin{array}{l}\text { - Corte dos mapas é feito individual devido serem } \\
\text { mapas especiais; }\end{array}$ \\
\hline 10 & Tapeçaria & 64 & $\begin{array}{l}\text { - Quebra do ritmo de tapeçagem, devido a } \\
\text { assimilação da forma de customização; } \\
\text { - Forma de customização do produto; }\end{array}$ \\
\hline 11 & $\begin{array}{l}\text { Verificação da } \\
\text { qualidade }\end{array}$ & 10 & - Verificação dos itens solicitados pelo cliente; \\
\hline 12 & Embalagem & 0 & $\begin{array}{l}\text { - Não há aumento de tempo pois essa etapa não } \\
\text { sofre alteração com a customização do produto; }\end{array}$ \\
\hline 13 & Expedição & 0 & $\begin{array}{l}\text { - Não há aumento de tempo pois essa etapa não } \\
\text { sofre alteração com a customização do produto; }\end{array}$ \\
\hline
\end{tabular}

Quadro 2. Comparação do custo médio de mão-de-obra do produto customizado em relação ao não customizado

\begin{tabular}{|c|c|c|c|c|}
\hline Etapa & Descrição & $\begin{array}{c}\text { Custo por } \\
\text { produto (R\$) }\end{array}$ & $\begin{array}{c}\text { Aumento do } \\
\text { tempo (\%) }\end{array}$ & $\begin{array}{c}\text { Custo por produto } \\
\text { customizado (R\$) }\end{array}$ \\
\hline 1 & Venda do produto & 21,66 & 27 & 27,51 \\
\hline 2 & Digitação do pedido & 0,60 & 54 & 0,92 \\
\hline 3 & Conferencia do pedido & 0,50 & 62 & 0,81 \\
\hline 4 & Suprimentos de materiais & 0,20 & 78 & 0,36 \\
\hline 5 & Compra de materiais & 0,50 & 15 & 0,58 \\
\hline 6 & Ordem de produção & 0,20 & 0 & 0,20 \\
\hline 7 & Encaixe do CAD & 1,78 & 100 & 3,56 \\
\hline 8 & Almoxarifado & 0,77 & 35 & 1,04 \\
\hline 9 & Marcenaria & 1,35 & 28 & 1,73 \\
\hline 9 & Corte de espuma & 0,70 & 70 & 1,19 \\
\hline 9 & Corte de tecido & 1,55 & 100 & 3,10 \\
\hline 10 & Tapeçaria & 5,60 & 64 & 9,18 \\
\hline 11 & Verificação da qualidade & 0,20 & 10 & 0,22 \\
\hline 12 & Embalagem & 0,77 & 0 & 0,77 \\
\hline 13 & Expedição & 0,58 & 0 & 0,58 \\
\hline & TOTAL & 36,96 & - & 51,74 \\
\hline
\end{tabular}

O aumento dos erros cometidos nas etapas do processo do produto, que na maioria das vezes há necessidade de refazer toda ou parte da etapa. Muitos erros causados por uma etapa podem induzir a erros de outras etapas, o que desencadearia o "efeito avalanche" no processo de produção. A frequência de ocorrências de erros foi medida através da entrada total de pedidos customizados em 30 dias, a qual foi passando por cada etapa do processo do produto (Quadro 3). 
Quadro 3. Erros cometidos em cada etapa do processo do produto customizado

\begin{tabular}{|c|c|c|c|}
\hline Etapa & Descrição & $\begin{array}{l}\text { Ocorrênci } \\
\text { a de erro } \\
(\%)\end{array}$ & $\begin{array}{c}\text { Observações } \\
\text { (Fatores relevantes para esse percentual) }\end{array}$ \\
\hline 1 & Venda do produto & 36 & $\begin{array}{l}\text { - Erro na forma de customização do produto, na } \\
\text { formação do preço, prazo de entrega, }\end{array}$ \\
\hline 2 & Digitação do pedido & 65 & $\begin{array}{l}\text { - Digitação errada nas observações externas da } \\
\text { forma de customização; }\end{array}$ \\
\hline 3 & $\begin{array}{l}\text { Conferencia do } \\
\text { pedido }\end{array}$ & 10 & $\begin{array}{l}\text { - Aceitação de tipo de customização que a } \\
\text { empresa não faz; }\end{array}$ \\
\hline 4 & $\begin{array}{l}\text { Suprimentos de } \\
\text { materiais }\end{array}$ & 10 & $\begin{array}{l}\text { - Erro no cálculo do material especial ou não } \\
\text { aquisição deste; }\end{array}$ \\
\hline 5 & Compra de materiais & 42 & - Fornecedor não entrega no prazo estipulado; \\
\hline 6 & Ordem de produção & 0 & - \\
\hline 7 & Encaixe do CAD & 56 & $\begin{array}{l}\text { - Erro no cálculo da medida e/ou na quantidade } \\
\text { de peças formação do novo mapa com os } \\
\text { encaixes do produto customizado }\end{array}$ \\
\hline 8 & Almoxarifado & 3 & - Separação do tecido errado; \\
\hline 9 & Marcenaria & 15 & - Erro no cálculo da metragem das ripas; \\
\hline 9 & Corte de espuma & 45 & $\begin{array}{l}\text { - Cálculo errado das novas metragens das } \\
\text { espumas; }\end{array}$ \\
\hline 9 & Corte de tecido & 5 & - Desatenção do operador; \\
\hline 10 & Tapeçaria & 20 & - Inversão dos tipos de acessórios; \\
\hline 11 & $\begin{array}{l}\text { Verificação da } \\
\text { qualidade }\end{array}$ & 12 & $\begin{array}{l}\text { - Erro na interpretação dos modos de } \\
\text { customização; } \\
\text { - Falta de melhor detalhamento; }\end{array}$ \\
\hline 12 & Embalagem & 0 & - \\
\hline 13 & Expedição & 0 & - \\
\hline
\end{tabular}

\section{DISCUSSÃO}

Constatou-se através do Quadro 1 que mais de 75\% das etapas produtivas sofrem um aumento no tempo de processamento nos produtos customizados quando comparados ao tempo de produção de produtos não personalizados.

No Quadro 2, verificou-se que o custo do tempo de mão-de-obra em produtos sem customização equivale a $R \$ 36,96 / h$ e o custo para os produtos customizados equivale a $R \$$ $51,74 / h$, o que representa para a empresa um aumento de custo na mão-de-obra de $40 \%$.

Verificou-se no Quadro 3, que existe uma alta porcentagem de erros cometidos nas etapas. Isso gera o retrabalho da etapa e conseqüentemente eleva o custo do processo do produto.

Tanto o aumento do tempo de processo quanto à freqüência de erros cometidos pelos colaboradores são reflexos de fatores tais como:

- Falta de treinamento dos funcionários; 
- Falta de elaboração de manual;

- Falta de especificação;

- Falta responsabilidade e qualidade no processo;

- Falta de investimento em tecnologia;

- Falta de metodologia no processo de forma a restringir a margem de erro;

- Falta de motivação dos funcionários.

No entanto esses impactos podem ser minimizados através de programas que combatam essas falhas. Para isso foram feitas sugestões de melhorias.

\subsection{Sugestões de Melhorias}

Foi apresentada a empresa as seguintes sugestões elaboradas para minimizar os impactos causados pelos produtos customizados:

- Treinamento dos funcionários de todos os setores;

- Conscientização dos funcionários quanto a sua importância e a sua responsabilidade perante o produto fabricado pela empresa;

- Implantação da cultura de responsabilidade e de autonomia de interromper o processo de produção ao detectar erro de produto, procedimento e/ou equipamento;

- Separação de produtos sem customização dos produtos customizados em determinadas etapas do processo do produto otimizando os tempos gastos nas etapas;

- Elaboração de manual explicativo dos produtos (ficha comercial);

- Catalogação dos produtos;

- Elaboração de manual explicativo das matérias primas;

- Catalogação das matérias-primas;

- Investimento em tecnologia de sistema de informação para facilitar e melhorara as etapas do processo;

- Criação de metodologias em cada etapa do processo de modo a criar uma seqüência operacional;

- Criação de fichas de ocorrências para cada etapa do processo de forma a obter informações mais precisas para atuar sobre elas;

- Determinar ou restringir os limites de customização de forma a criar parâmetros a serem seguidos. 


\section{CONCLUSÃO}

O sucesso da empresa está intimamente ligado à satisfação das necessidades implícitas e explicitas dos clientes. Para isso as empresas estão focando cada vez mais na personalização, especialização, sofisticação e tecnologia em produtos e processos.

A empresa a qual foi feito o estudo de caso, considera-se muito mais competitiva que as empresas que atuam no mesmo ramo e que não possuem essa flexibilidade de produção. Com produtos destinados aos estratos superiores de renda que consideram os paradigmas da massificação do produto inadequada aos seus padrões de vida, as suas exigências e as suas peculiaridades, a empresa avalia o nicho de mercado que adquirem os produtos customizados como ótimo e forte potencial de consumo, disponibilizando-se a atender as especificações dos clientes mesmo havendo impactos no seu processo de produção.

A empresa que desejar adotar o paradigma da customização maciça deverá estar apta para combater os impactos causados no processo de produção, de modo a reduzi-los o máximo possível, pois depois de superados, os princípios da customização maciça trarão em diversos setores da empresa maiores vantagens competitivas que os princípios da produção em massa.

\section{REFERÊNCIAS}

CARVALHO JÚNIOR, J. M. de. Estratégias de produção: a manufatura como arma competitiva, um estudo de caso. 1997. 148 p. Dissertação (Mestrado) - Escola de Administração, Universidade Federal do Rio Grande do Sul, Porto Alegre, 1997.

COUTINHO, L.; FERRAZ, J. C. (coord.). Estudo da competitividade da indústria brasileira. Campinas: Papirus / Editora da Universidade Estadual de Campinas, 1995.

GUERREIRO, R.; MEGLIORINI, E. A percepção dos gestores sobre fatores competitivos nas empresas produtoras de bens de capital sob encomendas: um estudo exploratório. Disponível em: < http://www.eac.fea.usp.br/congressousp/congresso3/trabalhos/2.pdf>. Acesso em: 30.mai.2006

GURGEL, Cláudio. A Gestão da Produtividade Excludente. Disponível em: < http://www.redem.buap.mx/word/2001gurgel.doc>. Acesso em: 27.mai.2006.

PINE II, B. Joseph. Personalizando Produtos e Serviços: Customização Maciça - A Nova Fronteira da Competição dos Negócios. São Paulo: Makron Books, 1994.

PORTER, Michel. Vantagem Competitiva. Rio de Janeiro: Campus, 1989.

SANTOS, F. C. A., PIRES, S. R. I.. Prioridades competitivas da administração estratégica da manufatura: um estudo de caso. In: ENANPAD, 22, Artigo OLS 03, Anais..., Foz do Iguaçu,1998. 
SILVA, Carlos Eduardo Sanches da. A Diferenciação de Serviços como uma Estratégia Competitiva. Disponível em: <http://www.iem.efei.br/sanches/Pesquisa/Artigos\%20 publicados/a20.PDF>. Acesso em: 27.mai.2006.

SLACK, N., CHAMBERS, S., HARLAND, C., HARRISON, A., JOHNSTON, R. Administração da produção. São Paulo: Atlas, 1997.

TOFFLER, Alvin. A Empresa Flexível. Rio de Janeiro: Record, 1985. 